\title{
The Interplay Between Attentional Strategies and Language Processing in High-functioning Adults with Autism Spectrum Disorder
}

\author{
Sophieke Koolen • Constance Th. W. M. Vissers • \\ Angelique W. C. J. Hendriks • Jos I. M. Egger • \\ Ludo Verhoeven
}

Published online: 21 June 2011

(C) The Author(s) 2011. This article is published with open access at Springerlink.com

\begin{abstract}
This study examined the hypothesis of an atypical interaction between attention and language in ASD. A dual-task experiment with three conditions was designed, in which sentences were presented that contained errors requiring attentional focus either at (a) low level, or (b) high level, or (c) both levels of language. Speed and accuracy for error detection were measured from 16 highfunctioning adults with ASD, and 16 matched controls. For controls, there was an attentional cost of dual level processing for low level performance but not for high level performance. For participants with ASD, there was an attentional cost both for low level and for high level performance. These results suggest a compensatory strategic use of attention during language processing in ASD.
\end{abstract}

Keywords Autism - Asperger's disorder - Attention · Language $\cdot$ Top-down control $\cdot$ Bottom-up processing

Part of this research was presented at the 18th Annual Meeting of Cognitive Neuroscience Society in San Francisco, 2011.

S. Koolen $(\bowtie) \cdot$ A. W. C. J. Hendriks .

J. I. M. Egger - L. Verhoeven

Behavioural Science Institute, Radboud University Nijmegen, P.O. Box 9104, 6500 HE Nijmegen, The Netherlands

e-mail: s.koolen@pwo.ru.nl

C. Th. W. M. Vissers · J. I. M. Egger

Centre of Excellence for Neuropsychiatry, Vincent van Gogh

Institute for Psychiatry, Venray, The Netherlands

C. Th. W. M. Vissers - J. I. M. Egger

Donders Institute for Brain, Cognition and Behaviour, Centre for

Cognition, Radboud University Nijmegen, Nijmegen,

The Netherlands
Autism Spectrum Disorder (ASD) is a developmental disorder that is characterized by several social and cognitive impairments, of which language problems are among the most profound (DSM-IV-TR, American Psychiatric Association 2000). A substantial amount of research examined language processing in ASD in the light of linguistic (dis)abilities, studying language as a module independent from other cognitive functions (e.g., Hudry et al. 2010; Kjelgaard and Tager-Flusberg 2001). However, recent neurocognitive perspectives emphasize the interconnection between language and other cognitive concepts (Perlovsky 2009). In line with this, the present study will focus on the interplay between attentional strategies and language processing in ASD, specifically in high-functioning adults with Autistic Disorder and Asperger's Disorder.

Autistic information processing in general is characterized by superior processing of local, detailed aspects of information, whereas global, contextual processing often seems reduced. Similar patterns have been demonstrated for language processing in ASD, although results remain somewhat mixed. Evidence for superior local processing is found in research on auditory speech processing, showing enhanced discrimination of speech pitches among autistic individuals as compared with typical controls (e.g., Heaton et al. 2008; Jarvinen-Pasley et al. 2008). Evidence for reduced global processing comes from studies that have found deficient use of semantic or contextual cues in the aid of free recall (Bowler et al. 2008). Similarly, in homograph tasks, a deficit has been observed in the use of sentence context for the correct pronunciation of homographs (Jolliffe and Baron-Cohen 1999). Nevertheless, when provided with explicit instructions, higher-level performance appears unimpaired and coherent linguistic processing can be achieved (e.g., Snowling and Frith 1986). 
Contemporary leading accounts attribute these processing differences to atypical perceptual processes. The common notion of these theories is that of an inherent superiority of low level, perceptual functions in ASD, suggesting a preference for detailed-focused processing. Weak central coherence theory (WCC; Frith 1989; Happé 1999; Happé and Frith 2006) posits that individuals with ASD show an innate preference for local, sensory information. Global processing is assumed not to be deficient per se; rather, it is thought to be impaired as a secondary result of superior local processing. Another main theoretical account, enhanced perceptual functioning theory (EPF; Mottron and Burack 2001; Mottron et al. 2006), predicts an advantage in perceptual processing among individuals with ASD, due to overfunctioning of perceptual brain regions. In contrast to WCC, EPF assumes that higher-order functions are unimpaired.

Both theoretical accounts imply that people with ASD can select from different processing levels, and that among these levels, they prefer to process low level information, and are better than typical individuals at doing so. This suggests then that the local processing style is voluntary. From our point of view, however, it might as well be that people with ASD focus on low level linguistic information out of necessity. We propose that the enhanced local processing could reflect an imperative strategic use of attention, rather than a different ability or preference, in processing language. In other words, we do not view the language problems in ASD as a result of language functions as such, but as a result of an atypical interaction between attention and language. Let us explain this alternative explanation in more detail.

Recent neuroimaging studies have shown reduced connectivity of functional regions in the brains of individuals with ASD (Just et al. 2004; Koshino et al. 2005). Connectivity, however, is essential in language processing, by promoting top-down modulation. Top-down modulation involves higher-order cognitive processes that bias attention towards specific aspects of information, based on expectations and prior knowledge (Miller 2000; Miller and Cohen 2004). This modulation thus enables the direction of attention to relevant aspects of the language (e.g., global, semantic or contextual aspects), while less important aspects (e.g., speech pitches, orthography, verbatim) are processed less efficiently and require less focused attention (Miller and Cohen 2004). Frith (2003) already suggested that the isolation of lower brain regions from higher brain regions in ASD will hinder the top-down modulation of information processing. As a consequence, language processing is probably less well controlled by attention.

We propose that, as a result of the suggested weakened top-down control of attention, autistic individuals might be forced to use an alternative strategy during language processing: bottom-up processing. A bottom-up approach involves a more detail-oriented style of processing, in which attention is systematically directed towards lower levels of information (Corbetta and Shulman 2002). In other words, given that attention is not directed towards higher-level information, the individual with ASD needs to take an alternative, systematic approach to the processing of language. It should be noted that this does not imply that people with ASD are unable to process higher-level information; their attention is just not directed towards these levels, as a result of which they are necessitated to use an alternative strategy for language processing. Hence, we expect the often observed enhancement of local processing in ASD to be the result of an attentional compensatory strategy. Previous findings of reduced global processing could then be explained by the attentional focus on detailed information. It could also clarify previous findings of improved performance after instructions (e.g., Snowling and Frith 1986). That is, the instructions serve as external 'top-down signals', enabling attention to be directed from lower levels of language towards higher levels, resulting in more global, coherent processing. To summarize, we propose that enhanced low level linguistic performance in ASD does not reflect a preference or superior ability to perceive low level information, but an attentional strategy to focus on low level information. The essential difference between our proposal and the aforementioned theories is that we expect the language abnormalities in ASD to be the result of the interplay between attention and language, rather than of language competency in itself.

The aim of the present study was to examine the interplay between attention and language in high-functioning adults with ASD. Accordingly, we developed a dual-task experiment, in which single level processing (focus either on local or on global aspects of language) was compared with dual level processing (focus on both local and global aspect of language). Based on our hypothesis of an attentional strategy, similar performance was expected for the autistic individuals and the typical individuals in the single level tasks. It was hypothesized that, as long as attention could be fully directed towards one single aspect of language, performance would be unimpaired and similar in both groups, regardless of the specific level (local or global) of language. In the dual level task, however, differences were expected between the groups. Given the assumption that for typical individuals the default processing mode is at higher levels of language (Gigerenzer and Goldstein 1996), we predicted that the control participants would perform similarly on high (global) levels of language in the dual level task as compared with the single level task, showing only deterioration of low (local) level processing in the dual level task. However, for people with 
ASD, deterioration of processing on both levels of language was expected in the dual level task as compared with their performance in the single level tasks. In the dual level task, both levels of language were expected to compete for the same attentional resources, thereby jeopardizing processing at both levels of language. If this would appear to be the case, it would indicate that the often observed enhancement in low level processing in ASD reflects an attentional strategy, rather than an innate enhanced ability to actually perceive low level information, as suggested by other theories.

\section{Methods}

\section{Participants}

Participants were 16 high-functioning patients with Autistic Disorder and Asperger's Disorder and 16 matched controls. Both groups consisted of 14 males and 2 females. All participants were native Dutch speakers, and had normal or corrected-to-normal vision. Patients with autism were selected for their diagnosis by a clinical psychologist or psychiatrist based on the DSM-IV criteria, from a mental health care institution and an institution specialized in autism spectrum disorders in the Netherlands. Exclusion criteria were diagnoses of Pervasive Developmental Disorder Not Otherwise Specified and co-morbid psychiatric disorders, and reading disabilities. Of the selected patients, eight patients had been diagnosed with Autistic Disorder and eight patients had been diagnosed with Asperger's Disorder. In order to verify the diagnosis, the Autism Diagnostic Observation Schedule (ADOS) (Lord et al. 1999), fourth Module, was administered by a licensed health psychologist. All patients met the ADOS-criteria for autism spectrum $(M=10.7$, range $=7-18)$.

The clinical and control group were matched on gender, age, intelligence and working memory (Table 1). Performance intelligence was assessed with the Raven Standard Progressive Matrices (Raven SPM). Verbal intelligence was measured with the Dutch version of the National Adult Reading Test (NART), which is a word reading test that consists of words that are irregular in their graphemephoneme correspondences and can thus only be pronounced correctly if known by the subject. The test was originally designed to estimate premorbid level of reading ability in people with brain damage, but has been shown to be a reliable and valid estimate of verbal intelligence in healthy controls as well (e.g., Bright et al. 2002; Schmand et al. 1992). Working memory capacity was assessed with the Letter-number sequencing test (subtest of the Wechsler Adult Intelligence Scale III). Groups did not significantly differ on age $(p=.54)$, performance intelligence $(p=.31)$, verbal intelligence $(p=.31)$, and working memory $(p=$ .18). Significant differences were found between ASD subgroups on age $(p=.03)$, performance intelligence $(p=$ $.01)$, and working memory capacity $(p=.01)$, yet, not on verbal intelligence $(p=.08)$.

Design

The study consisted of a mixed between-within subjects design. As described earlier, a dual-task experiment was developed to measure the role of attention during processing at different levels of language. The experiment included three conditions with different attentional instructions, to which all participants were exposed. In the low level condition, participants were instructed to focus attention on orthographic errors (typing errors), which required processing of words at a low, perceptual level. In the high level condition, participants were instructed to focus attention on syntactic errors. This required more global, higher level processing, in which words needed to be processed in relation to each other. In the dual level condition, participants were instructed to focus attention both on orthographic errors and on syntactic errors. As a result, there were two factors (orthography and syntax), both consisting of two levels (single level versus dual level). Group (ASD versus control) was the between-subjects factor. Dependent variables were the accuracy percentages and reaction times for the detections of the different error types in the different conditions.

\section{Materials}

In order to measure processing at different levels of language, a set of 256 Dutch sentences was developed. The sentences required no or only minimal social
Table 1 Means and standard deviations for age, performance intelligence, verbal intelligence and working memory capacity for the total ASD group, the ASD subgroups, and the control group

\begin{tabular}{|c|c|c|c|c|c|c|c|c|}
\hline & \multicolumn{2}{|l|}{ Age } & \multicolumn{2}{|c|}{ Performance IQ } & \multicolumn{2}{|c|}{ Verbal IQ } & \multicolumn{2}{|c|}{ WM capacity } \\
\hline & M & SD & M & SD & M & $\mathrm{SD}$ & M & SD \\
\hline ASD group total $(n=16)$ & 27.5 & 6.5 & 120.6 & 10.1 & 99.0 & 7.3 & 11.9 & 3.1 \\
\hline Autistic disorder $(n=8)$ & 24.0 & 5.7 & 114.6 & 10.9 & 95.8 & 6.9 & 10.0 & 2.5 \\
\hline Asperger's disorder $(n=8)$ & 31.0 & 5.6 & 126.6 & 4.0 & 102.2 & 6.6 & 13.8 & 2.4 \\
\hline Control group $(n=16)$ & 26.3 & 4.0 & 123.8 & 5.7 & 101.8 & 7.6 & 10.6 & 1.8 \\
\hline
\end{tabular}


representations. Of each sentence, four variants were made: an experimental sentence with an orthographic error, an experimental sentence with a syntactic error and two control sentences. The errors in the experimental sentences always occurred at the verb position, regardless of the type of the error. The orthographic errors were reflected by typing errors in the verb, in which one letter had been replaced by another, incorrect letter:

'The dog berks (barks) at the old neighbour.'

The syntactic errors were presented in the form of subject-verb agreement violations, which are characterized by an inconsistency in the number of the subject and the number of the verb:

'Sarah takes the broom and sweep (sweeps) the floor.'

In order to prevent expectancy about the position of the target word to affect the results, eight different sentence structures were developed, in which the position of the target varied from the second to the ninth word position (for an overview see "Appendix"). These sentence structures were equally distributed across conditions.

The four variants of each sentence were assigned to four different lists, to ensure that each sentence could appear in every form, albeit to different participants. Each list of 256 sentences was divided into four blocks of 64 sentences. One block represented the low level condition (32 experimental sentences with orthographic error, 32 control sentences), one represented the high level condition (32 experimental sentences with syntactic error, 32 control sentences), and two represented the dual level condition (16 experimental sentences with orthographic error, 16 experimental sentences with syntactic error, 32 control sentences within each block).

\section{Procedure}

Before the start of the study, approval was obtained from the Medical Ethical Committee. Participants were seated in a sound-attenuating room, approximately $80 \mathrm{~cm}$ from a computer screen. A response device with a small button was placed in front of the participant. Sentences were presented word-by-word at the center of the computer screen, using a rapid serial visual presentation technique. Word duration was $300 \mathrm{~ms}$, the stimulus-onset asynchrony was $500 \mathrm{~ms}$. Each sentence was preceded by a fixation cross (duration $300 \mathrm{~ms}$ ), which was followed by a blank screen (duration $200 \mathrm{~ms}$ ). Sentence final words were marked by a period and followed by an inter-trial interval of $2,000 \mathrm{~ms}$.

The duration of each block was approximately $8.5 \mathrm{~min}$. The four blocks were separated by breaks of $2 \mathrm{~min}$. Each block was preceded by instructions and six practice trials.
Within blocks, the sentences were randomly presented. The order of the blocks was counterbalanced across participants, with the dual level blocks always being presented consecutively, in order to simplify task instructions. The total duration of the experiment was $40-45 \mathrm{~min}$ on average.

\section{Data Analysis}

For each participant, reaction times were measured from the time when the error appeared until the participant responded. Individual cut-off values were calculated per error per condition, as the mean \pm 2 standard deviations. Values exceeding the individual cut-off scores were removed from the data set. Overall, this resulted in a $5.93 \%$ removal of the data (low level condition: ASD group 7\%, Control group 5.9\%; high level condition: ASD group $5.7 \%$, Control group 6.7\%; dual level condition for orthographic errors: ASD group 6.3\%, Control group 5.1\%; dual level condition for syntactic errors: ASD group $4.5 \%$, Control group $7.2 \%$ ).

For the analysis of the data, first, accuracy was calculated per error type per condition as the number of detected errors divided by the total number of experimental sentences within the condition. Given that the normalities of the accuracy percentages per condition were strongly violated, nonparametric tests were performed to investigate differences in accuracy across conditions for the two groups (Friedman tests) and differences between groups per error type (Mann-Whitney $U$ tests). For the analysis of the reaction times, a repeated measures ANOVA and a MANOVA were performed to analyze the differences between conditions as well as between participants.

\section{Results}

Overviews of the means and standard deviations of the accuracy percentages and reaction times of the ASD group and the control group in the different conditions are provided in Tables 2 and 3.

\section{Accuracy}

Before analysis of the reaction times for the error detection, the accuracy of this error detection was examined. For both groups it was examined whether the accuracy with which errors were detected differed between conditions. Based on Friedman tests for repeated measures, differences in error detection between conditions were found neither in the ASD group nor in the control group. Accuracy percentages for the detection of orthographic errors did not differ significantly between the low level and the dual level 
Table 2 Means and standard deviations for accuracy percentages of error detection per error type per condition for the total ASD group, the ASD subgroups, and the control group

\begin{tabular}{|c|c|c|c|c|c|c|c|c|}
\hline & \multicolumn{8}{|c|}{ Accuracy in $\%$} \\
\hline & \multicolumn{2}{|c|}{ Orthography low level } & \multicolumn{2}{|c|}{ Orthography dual level } & \multicolumn{2}{|c|}{ Syntax high level } & \multicolumn{2}{|c|}{ Syntax dual level } \\
\hline & M & SD & M & SD & M & SD & M & SD \\
\hline ASD group total $(n=16)$ & 94.5 & 4.8 & 95.7 & 6.1 & 90.0 & 10.2 & 87.1 & 11.0 \\
\hline Autistic disorder $(n=8)$ & 93.0 & 6.0 & 93.8 & 8.2 & 85.2 & 13.5 & 81.6 & 10.0 \\
\hline Asperger's disorder $(n=8)$ & 96.1 & 2.8 & 97.7 & 2.2 & 94.1 & 3.5 & 92.6 & 9.6 \\
\hline Control group $(n=16)$ & 95.3 & 2.3 & 95.3 & 3.6 & 93.8 & 5.4 & 92.0 & 6.2 \\
\hline
\end{tabular}

Table 3 Means and standard deviations for reaction times in milliseconds of error detection per error type per condition for the total ASD group, the ASD subgroups, and the control group

\begin{tabular}{|c|c|c|c|c|c|c|c|c|}
\hline & \multicolumn{8}{|c|}{ Reaction times in $\mathrm{ms}$} \\
\hline & \multicolumn{2}{|c|}{ Orthography low level } & \multicolumn{2}{|c|}{ Orthography dual level } & \multicolumn{2}{|c|}{ Syntax high level } & \multicolumn{2}{|c|}{ Syntax dual level } \\
\hline & M & SD & M & SD & M & SD & M & SD \\
\hline ASD group total $(n=16)$ & 632.3 & 140.6 & 655.3 & 132.2 & 800.0 & 208.4 & 864.6 & 216.7 \\
\hline Autistic disorder $(n=8)$ & 690.6 & 170.0 & 718.1 & 159.7 & 890.8 & 241.6 & 967.2 & 243.0 \\
\hline Asperger's disorder $(n=8)$ & 573.9 & 75.3 & 592.6 & 54.5 & 709.2 & 126.1 & 762.0 & 132.3 \\
\hline Control group $(n=16)$ & 598.1 & 61.2 & 616.9 & 56.8 & 740.9 & 92.1 & 746.2 & 93.2 \\
\hline
\end{tabular}

condition, both for the ASD group $\left(\chi^{2}=2.78, p=.10\right)$ and for the control group $\left(\chi^{2}=.00, p>.99\right)$. Similarly, accuracy percentages for syntactic error detection did not differ significantly between the high level and the dual level condition, both for the ASD group $\left(\chi^{2}=1.33\right.$, $p=.25)$ and for the control group $\left(\chi^{2}=.60, p=.44\right)$. Hence, the accuracy with which orthographic as well as syntactic errors were detected did not differ based on the condition in which they were presented. Furthermore, it was analyzed whether the ASD and control group differed in the accuracy with which they detected the errors in the sentences. Mann-Whitney $U$ tests showed no significant differences between the ASD group and the control group in their accuracy of error detection for orthographic errors in the low level condition $(U=127, z=-.04, p=.97)$, orthographic errors in the dual level condition $(U=102$, $z=-1.02, p=.31)$, syntactic errors in the high level condition $(U=92.5, z=-1.12, p=.26)$, and syntactic errors in the dual level condition $(U=98.5, z=-1.13$, $p=.26$ ). Both groups were equally accurate in the detection of the different error types.

\section{Reaction Times}

The main analysis of the present study concerned the interaction between language and attention within the two separate groups of participants. A repeated measures ANOVA was conducted on reaction times for error detection, with orthographic errors (low level condition versus dual level condition) and syntactic errors (high level condition versus dual level condition) as the within-subjects factors, and group (ASD vs. control) as the betweensubjects factor. It was examined whether the reaction times for detection of orthographic errors as well as syntactic errors differed based on the condition in which the errors were presented, and if so, whether these patterns differed between the two groups of participants. A graphical overview of the results is provided in Fig. 1. First, a significant main effect was found of the condition in which orthographic errors were presented (low level versus dual level) on reaction times for error detections $(F(1,30)=108.12$, $p<.001)$. There was no significant interaction effect of the condition of orthographic errors and group (ASD versus control $)(F(1,30)=2.82, p=.10)$. As expected, both groups were significantly slower in detecting orthographic errors in the dual level condition, as compared to the low level condition. Second, a significant main effect was found of the condition in which syntactic errors were presented (high level versus dual level) on reaction times for error detection $(F(1,30)=14.94, p=.001)$. This effect, however, was qualified by a significant interaction between the syntactic condition and group $(F(1,30)=$ 4.84, $p=.04)$.

In order to further explore the interaction effect, simple effects analyses were performed. Results showed that participants with ASD had significantly longer reaction times on the syntactic errors in the dual level condition, as compared to the high level condition $(F(1,15)=6.94$, 


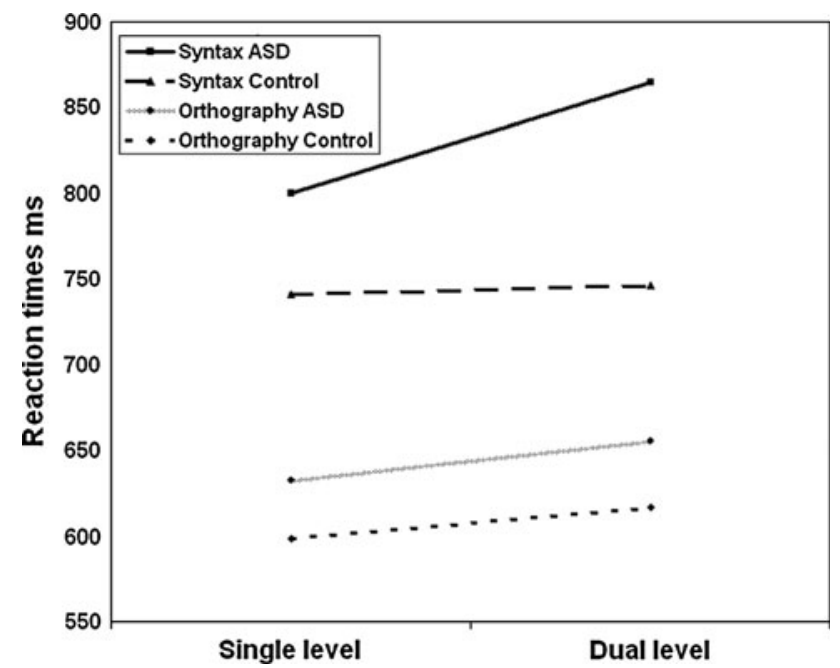

Fig. 1 Reaction times in milliseconds of the ASD group and the control group for the detection of orthographic errors and syntactic errors in the single level and dual level conditions

$p=.02$ ). Reaction times of the control participants on the syntactic errors did not differ significantly across conditions $(F(1,15)<1, p=.65)$. These results were in line with our expectations; whereas participants with ASD showed increases of reaction times both for the orthographic errors and for the syntactic errors in the dual level condition as compared to the single level conditions, control participants showed increases only for the orthographic errors, but not for the syntactic errors. This pattern was further supported by the differences between the ASD group and the control group for their reaction times per error type per condition. A MANOVA was performed with the four measurements of reaction times as the dependent variables and Group (ASD versus control) as the independent factor. No significant differences were found between the ASD group and the control group in their reaction times for detection of orthographic errors in the low level condition $(F(1,30)<1, p=.38)$, orthographic errors in the dual level condition $(F(1,30)=1.14$, $p=.29$ ), and syntactic errors in the high level condition $(F(1,30)=1.08, p=.31)$. However, a significant group effect was found for the speed of the detection of syntactic errors in the dual level condition $(F(1,30)=4.03$, $p=.05)$. Participants in the ASD group were significantly slower in detecting syntactic errors in the dual level condition than participants in the control group.

\section{Effect of Diagnosis}

In addition to the main analyses described above, a short comment should be made on the comparison between the participants with a diagnosis of Autistic Disorder and Asperger's Disorder. In line with the aforementioned results, logically, there was a significant main effect of the condition in which the orthographic errors were presented on the reaction times for error detections $(F(1,14)=50.26$, $p<.001)$, as well as of the condition in which the syntactic errors were presented $(F(1,14)=12.29, p=.003)$. However, there was neither a significant interaction effect on the reaction times between the participants' diagnoses and the condition in which orthographic errors were presented $(F(1,14)=1.85, p=.20)$, nor between the participants' diagnoses and the condition in which syntactic errors were presented $(F(1,14)<1, p=.53)$. Participants with Autistic Disorder and with Asperger's Disorder both were slower detecting orthographic and syntactic errors in the dual level condition than in the single level conditions. Furthermore, no significant differences were found between the Autistic Disorder participants and the Asperger's Disorder participants in their reaction times for detection of orthographic errors in the low level condition ( $F$ (1, $14)=3.16, p=.10$ ), and syntactic errors in the high level condition $(F(1,14)=3.55, p=.08)$. However, (marginally) significant effects of diagnosis were found for the speed of the detection of orthographic errors in the dual level condition $(F(1,14)=4.43, p=.05)$ and of syntactic errors in the dual level condition $(F(1,14)=4.40, p=.06)$. In short, participants with a diagnosis of Autistic Disorder did not differ from those with a diagnosis of Asperger's Disorder on the speed with which they detected errors in the single level conditions, yet, they were slower in their error detection in the dual level condition. Nonetheless, although participants with Asperger's Disorder were faster in the dual level condition than participants with Autistic Disorder, the actual pattern of a processing delay in the dual level conditions as compared with the single level conditions did not differ between both groups.

\section{Discussion}

The aim of the present study was to examine the interaction between attention and language in high-functioning adults with ASD as compared to typical controls. It was hypothesized that the language atypicalities observed in ASD result from an attentional strategy, rather than from a language (in)competency as such. A dual-task experiment was developed to evaluate the effect of attentional focus during the processing of different levels of language. Results showed that the participants with ASD did not differ from control participants with respect to the accuracy with which they processed different levels of language. Furthermore, neither the participants with ASD nor the control participants showed differences in their language processing accuracy when attention was directed either to orthography or to syntax, as compared to when attention was directed to 
both levels of language simultaneously. Of special interest were the findings with respect to the speed of language processing. In the dual level condition, in which both low level and high level linguistic information needed to be processed, control participants showed a decrease of speed at low level processing, but not at high level processing, in comparison with the single level conditions. For the autistic participants, however, speed was reduced both at low level and at high level processing in the dual level condition, as compared to the single level conditions.

The results seem supportive of our hypothesis of a different, strategic use of attention in ASD. The importance of the role of attention during language processing becomes evident when comparing performance in the single levels conditions with performance in the dual level condition. In the single level conditions, attention could be fully directed either towards low level, orthographic information (low level condition) or towards high level, syntactic information (high level condition). Both groups of participants were equally fast in these conditions. In the dual level condition, however, participants were instructed to process both levels of language. For the control participants, this dual level task requirement came at the expense only of low level, orthographic processing. High level, syntactic information was processed equally fast as compared to the single level condition. For the autistic participants, by contrast, the task requirement of the dual level condition came at the cost of both low level and high level language processing, as shown by an overall processing delay. This suggests that it is the interaction between attention and language, rather than the language ability in itself, that is different for people with ASD and people without ASD.

The results of the control participants are in line with the general tendency of typical individuals to attend to higherlevel aspects, rather than more local, detailed aspects of language (Gigerenzer and Goldstein 1996). This tendency reflects a mechanism of so-called top-down control, in which knowledge about, for instance, plausible syntactic structures determines to which parts of the information attention needs to be directed (Miller 2000; Miller and Cohen 2004). Top-down control of attention enables the individual to process high level information (in this case the syntactic structure) relatively fast and efficiently, because it only requires the use of a small proportion of the available information (Eulitz and Hanneman 2010). In case of multilevel processing, attention is directed towards higher-level structures, whereas low level information is processed with less focused attention (Miller and Cohen 2004). In the present experiment, this top-down mechanism was reflected by stability of syntactic processing across conditions, and concurrent deceleration of low level processing in the dual level condition as compared with the low level condition.
For the autistic participants, however, such top-down effect appeared absent. When both levels of language needed to be processed simultaneously, attention was not directed to either the one or the other. Instead, both levels were processed less efficiently, reflected by an overall increase of reaction times. This suggests that, whereas typical individuals rely on top-down control of attention during language processing, people with ASD do not or do so to a lesser extent. These findings are in line with the earlier proposal of Frith (2003), stating that autistic cognition is the result of reduced functioning of the feedback control-system that should typically modulate early sensory processing. Similarly, neurobiological evidence suggested that the neural basis of autistic language problems involves underconnectivity between separate brain regions responsible for language processing (Just et al. 2004). Due to the subsequent disruption of information integration, higher-level, coherent processing would be impaired. The underconnectivity is thus proposed to result in diminished controlled processing.

Alternatively, as the present results suggest, people with ASD might compensate for weakened top-down control by a different, strategic use of attention. That is, despite absence of the typical top-down modulation of attention, both levels of language were still processed accurately in the dual level condition. Orthographic as well as syntactic information appeared to be evaluated correctly, although more slowly and thus probably less efficiently. In our view, reduced top-down control might require people with ASD to apply a more systematic, bottom-up approach of language processing (Corbetta and Shulman 2002), in which a linguistic representation is built out of the separate constituents of a sentence or text. In other words, in order to make sense of the linguistic information, all available aspects need to be attended to. Such a bottom-up attentional strategy could account for the enhanced low level performance often found in previous studies (Heaton et al. 2008; Jarvinen-Pasley et al. 2008), given that details receive attentional focus and are thus processed more thoroughly. At the same time, such a strategy may hinder the formation of a coherent, global linguistic representation, explaining the reduced high level performance often observed in ASD (Bowler et al. 2008; Jolliffe and BaronCohen 1999). Furthermore, it can explain why, when given explicit attentional cues, autistic individuals are able to process higher levels (Snowling and Frith 1986). As long as there is only one task, the top-down absence can be compensated by a systematic, attentional focus. Such a bottom-up processing style, however, will be more attention-consuming than a top-down processing style. Therefore, the use of an attentional compensatory strategy will inevitably lead to processing problems when linguistic information is complex, or when multiple linguistic tasks 
need to be performed at the same time. It was exactly this effect that we found in the present experiment. In the single level conditions, participants with ASD were as fast as participants without ASD. Nonetheless, in the dual level condition, speed of processing was reduced for both levels.

It should be noted that attention was not measured directly in this study, and conclusions of an interaction between attention and language should thus be drawn with caution. However, the experimental design allows us to compare within participants the processing performance in tasks that were linguistically similar but administered under different conditions. An explanation in terms of a true deficit in language or nonlanguage functions would subsequently be reflected in both single and dual level conditions. The finding that the detection of orthographic and syntactic errors depended upon condition (single or dual level processing) and not on linguistic level (orthography or syntax), suggests that attentional processes rather than linguistic processes are different in people with ASD. Obviously, the interplay between attention and language suggested by the current results should be further explored in future research, measuring attention more directly. Implicit methods with a high time resolution such as Event Related Potentials could provide valuable information into this matter.

Following the aforementioned reasoning, the results appear inconsistent with WCC and EPF theories. According to WCC theory (Frith 1989; Happé 1999; Happé and Frith 2006), people with ASD have a so-called local cognitive style in which they prefer and are biased to processing low level information, whereas people without ASD have a global cognitive style in which they are biased towards high level information. EPF theory (Mottron and Burack 2001; Mottron et al. 2006) states that ASD is characterized by overactivity of perceptual brain regions, which results in enhanced local processing abilities. Examining the assumptions of a local cognitive style or superior low level ability in light of the present dual-task experiment, one would expect the participants with ASD to (a) be more accurate at processing low levels of language than typical controls, and (b) be equally fast in low level processing in the dual level condition and the low level condition, regardless of high level task and performance. However, this was not the case. First of all, there were no differences between the participants with and without ASD in their accuracy of language processing (neither for low level nor for high level aspects of language), indicating that the perception of the people with ASD was not superior or inferior to that of the people without ASD. Even more importantly, the speed with which the participants with ASD processed language decreased in the dual level condition, indicating that their perception was sensitive to the (attentional) demands of the task. Hence, although the present findings support WCC's and EPF's assumptions of perceptual processes being atypical in ASD, the results do not agree with the proposed low level preference or superiority as an explanation for this atypicality.

Interestingly, although group sizes are small, a similar interaction between attention and language was observed for people with Autistic Disorder and Asperger's Disorder. It was found that, although in the dual level condition participants with Asperger's Disorder were faster than those with Autistic Disorder in processing low level and high level information, both groups showed the pattern of a general processing delay in the dual level condition in comparison with the single level conditions. This suggests that all participants with ASD used a similar attentional strategy during language processing, regardless of their specific diagnoses. The fact that participants with Asperger's Disorder were faster suggests that they are more skilled in applying a compensatory strategy during language processing. It seems likely that their larger working memory capacity, as found in this study, has enabled them to become more proficient using attention strategically, resulting in better language performance on tests and in daily life than people with Autistic Disorder. Hence, the current clinical description of an absence of a general delay in language in Asperger's Disorder (DSM-IV-TR, American Psychiatric Association 2000) might merely indicate a more advanced use of a compensatory strategy, rather than a true absence of an atypical processing pattern as such. People with Asperger's Disorder might simply be better able to set in a compensatory strategy; because of this, their atypical language processing style does not show up at the behavioral level. The current findings shed light on the ongoing debate on whether Autistic Disorder and Asperger's Disorder are discrete disorders or represent different expressions of one underlying pathogenesis and are thus settled on the same continuum. The presence of a similar atypical interaction between attention and language for Autistic Disorder and Asperger's Disorder confirms recent statements that both disorders share a common etiology and developmental neuropathology, with Asperger's Disorder being a mild form of Autistic Disorder (Ritvo et al. 2008; Ghaziuddin 2010). The results therefore are supportive of the dimensional approach suggested for the DSM-V, rather than the currently used categorical one in DSM-IV-TR. In the dimensional approach, more dimensional measures and descriptions are incorporated in order to better close up with behavioral phenotypes and to go across current diagnostic boundaries (e.g., Kupfer et al. 2008). Accordingly, Autistic Disorder and Asperger's Disorder are viewed as behavioral expressions of one underlying disorder, albeit with different symptom severities.

The most important conclusion from the present study is that language atypicalities in people with ASD might not result from language (dis)abilities as such, but are more 
likely the result of a different interplay between attention and language. In line with recent neurocognitive perspectives, these findings emphasize the importance of focusing on language not as an independent competency, but as a functional entity continuously interacting with other cognitive systems. Such an approach could provide relevant suggestions for future directions in the search for the nature of language processes in ASD.

Acknowledgments We thank the department Circuit Autisme Spectrum Stoornissen en ADHD (head: W. Verbeeck, MD) of the Vincent van Gogh Institute for Psychiatry and Stichting Autismetotaal.nl (head: B. van IJken, MD) for their cooperation. We are grateful to all participants who volunteered in this study. Thanks are extended to Hubert Voogd for his help in designing the experimental software used in this study.

Open Access This article is distributed under the terms of the Creative Commons Attribution Noncommercial License which permits any noncommercial use, distribution, and reproduction in any medium, provided the original author(s) and source are credited.

Table 4 Examples of eight different sentence structures with varying target word positions, for the orthographic errors and the syntactic errors

\begin{tabular}{|c|c|c|}
\hline Target word position & Condition & Dutch sentence and translated sentence \\
\hline \multirow[t]{2}{*}{ 2nd } & Orthographic error & $\begin{array}{l}\text { Peter wackt (wacht) bij de drukke bushalte in de stad } \\
\text { Peter waitz (waits) at the crowded bus stop in the city }\end{array}$ \\
\hline & Syntactic error & $\begin{array}{l}\text { Peter wachten (wacht) bij de drukke bushalte in de stad } \\
\text { Peter wait (waits) at the crowded bus stop in the city }\end{array}$ \\
\hline \multirow[t]{2}{*}{$3^{\text {rd }}$} & Orthographic error & $\begin{array}{l}\text { De hond bleft (blaft) naar de oude buurman } \\
\text { The dog } \underline{\text { berks (barks) at the old neighbour }}\end{array}$ \\
\hline & Syntactic error & $\begin{array}{l}\text { De hond blaffen (blaft) naar de oude buurman } \\
\text { The dog } \underline{\text { barks }} \text { (barks) at the old neighbour }\end{array}$ \\
\hline \multirow[t]{2}{*}{ 4th } & Orthographic error & $\begin{array}{l}\text { Het ernstige ongeluk gedeurt (gebeurt) bij het kapotte stoplicht } \\
\text { The serious accident } \underline{\text { happems (happens) at the broken traffic-light }}\end{array}$ \\
\hline & Syntactic error & $\begin{array}{l}\text { Het ernstige ongeluk gebeuren (gebeurt) bij het kapotte stoplicht } \\
\text { The serious accident happen (happens) at the broken traffic-light }\end{array}$ \\
\hline \multirow[t]{2}{*}{5 th } & Orthographic error & $\begin{array}{l}\text { De enthousiaste duiker die zvemt (zwemt) met de studenten heeft ervaring } \\
\text { The enthusiastic diver who swins (swims) with the students is experienced }\end{array}$ \\
\hline & Syntactic error & $\begin{array}{l}\text { De enthousiaste duiker die zwemmen (zwemt) met de studenten heeft ervaring } \\
\text { The enthusiastic diver who } \underline{\text { swim (swims) with the students is experienced }}\end{array}$ \\
\hline \multirow[t]{2}{*}{ 6th } & Orthographic error & $\begin{array}{l}\text { Sarah pakt de bezem en veagt (veegt) de vloer } \\
\text { Sarah takes the broom and sweaps (sweeps) the floor }\end{array}$ \\
\hline & Syntactic error & $\begin{array}{l}\text { Sarah pakt de bezem en vegen (veegt) de vloer } \\
\text { Sarah takes the broom and sweep (sweeps) the floor }\end{array}$ \\
\hline \multirow[t]{2}{*}{7 th } & Orthographic error & $\begin{array}{l}\text { De man die met zijn collega's afspreeht (afspreekt) komt altijd te laat } \\
\text { The man who with his colleagues meefs (meets) is always too late } \\
\text { The man who meefs (meets) with his colleagues is always too late }\end{array}$ \\
\hline & Syntactic error & $\begin{array}{l}\text { De man die met zijn collega's afspreken (afspreekt) komt altijd te laat } \\
\text { The man who with his colleagues meet (meets) is always too late } \\
\text { The man who meet (meets) with his colleagues is always too late }\end{array}$ \\
\hline \multirow[t]{2}{*}{ 8th } & Orthographic error & $\begin{array}{l}\text { De leraar die bij de kinderen zit praet (praat) over het huiswerk } \\
\text { The teacher who with the children sits talhs (talks) about the homework } \\
\text { The teacher who sits with the children talhs (talks) about the homework }\end{array}$ \\
\hline & Syntactic error & $\begin{array}{l}\text { De leraar die bij de kinderen zit praten (praat) over het huiswerk } \\
\text { The teacher who with the children sits talk (talks) about the homework } \\
\text { The teacher who sits with the children talk (talk) about the homework }\end{array}$ \\
\hline \multirow[t]{2}{*}{ 9th } & Orthographic error & $\begin{array}{l}\text { De slimme auteur heeft een briljant idee en sckrijft (schrijft) een boek } \\
\text { The intelligent author has a brilliant idea and writez (writes) a book }\end{array}$ \\
\hline & Syntactic error & $\begin{array}{l}\text { De slimme auteur heeft een briljant idee en schrijven (schrijft) een boek } \\
\text { The intelligent author has a brilliant idea and write (writes) a book }\end{array}$ \\
\hline
\end{tabular}

\section{Appendix}

\section{See Table 4.}




\section{References}

American Psychiatric Association. (2000). Diagnostic and statistical manual of mental disorders (4th ed.). Washington, DC: Author.

Bowler, D. M., Gaigg, S. B., \& Gardiner, J. M. (2008). Effects of related and unrelated context on recall and recognition by adults with high-functioning autism spectrum disorder. Neuropsychologia, 46, 993-999.

Bright, P., Jaldow, E., \& Kopelman, M. D. (2002). The National Adult Reading Test as a measure of premorbid intelligence: A comparison with estimates from demographic variables. Journal of International Neuropsychological Society, 8, 847-854.

Corbetta, M., \& Shulman, G. L. (2002). Control of goal-directed and stimulus-driven attention in the brain. Nature Reviews Neuroscience, 3, 201-215.

Eulitz, C., \& Hanneman, R. (2010). On the matching of top-down knowledge with sensory input in the perception of ambiguous speech. BMC Neuroscience, 11, 1471-2202.

Frith, U. (1989). Autism: Explaining the enigma. Oxford, UK: Blackwell.

Frith, C. (2003). What do neural imaging studies tell us about the neural basis of autism? Novartis Foundation Symposium, 251, $149-166$

Ghaziuddin, M. (2010). Brief report: Should the DSM V drop Asperger Syndrome? Journal of Autism and Developmental Disorder, 40, 1146-1148.

Gigerenzer, G., \& Goldstein, D. G. (1996). Reasoning the fast and frugal way: Models of bounded rationality. Psychological Review, 103(4), 650-669.

Happé, F. (1999). Autism: cognitive deficit or cognitive style. Trends in cognitive sciences, 3(6), 216-222.

Happé, F., \& Frith, U. (2006). The weak coherence account: Detailfocused cognitive style in autism spectrum disorders. Journal of Autism and Developmental Disorders, 36(1), 5-25.

Heaton, P., Hudry, K., Ludlow, A., \& Hill, E. (2008). Superior discrimination of speech pitch and its relationship to verbal ability in autism spectrum disorders. Cognitive Neuropsychology, 25(6), 771-782.

Hudry, K., Leadbitter, K., Temple, K., Slonims, V., McConachie, H., Aldred, C., et al. (2010). Preschoolers with autism show greater impairment in receptive compared with expressive language abilities. International Journal of Language and Communication Disorders, 45(6), 681-690.

Jarvinen-Pasley, A., Wallace, G. L., Ramus, F., Happé, F., \& Heaton, P. (2008). Enhanced perceptual processing of speech in autism. Developmental Science, 11(1), 109-121.
Jolliffe, T., \& Baron-Cohen, S. (1999). A test of central coherence theory: linguistic processing in high-functioning adults with autism or Asperger syndrome: is local coherence impaired? Cognition, 71, 149-185.

Just, M. A., Cherkassky, V. L., Keller, T. A., \& Minshew, N. J. (2004). Cortical activation and synchronization during sentence comprehension in high-functioning autism: evidence of underconnectivity. Brain, 127, 1811-1821.

Kjelgaard, M. M., \& Tager-Flusberg, H. (2001). An investigation of language impairment in autism: Implications for genetic subgroups. Language and Cognitive Processes, 16, 287-308.

Koshino, H., Carpenter, P. A., Minshew, N., Cherkassky, V. L., Keller, T., \& Just, M. A. (2005). Functional connectivity in an fMRI working memory task in high-functioning autism. Neuroimage, 24, 810-821.

Kupfer, D. J., Regier, D. A., \& Kuhl, E. A. (2008). On the road to DSM-V and ICD-11. European Archives of Psychiatry and Clinical Neuroscience, 258, 2-6.

Lord, C., Rutter, M., DiLavore, P. C., \& Risi, S. (1999). Autism diagnostic observation schedule. Los Angeles, CA: Western Psychological Services.

Miller, E. K. (2000). The prefrontal cortex and cognitive control. Nature Reviews Neuroscience, 1, 59-65.

Miller, E. K., \& Cohen, J. D. (2004). An integrative theory of prefrontal cortex function. Annual Review of Neuroscience, 24, 167-202.

Mottron, L., \& Burack, J. (2001). Enhanced perceptual functioning in the development of autism. In J. A. Burack, T. Charman, N. Yirmiya, \& P. R. Zelazo (Eds.), The development of autism: Perspectives from theory and research (pp. 131-148). Mahwah, NJ: Erlbaum.

Mottron, L., Dawson, M., Soulieres, I., Hubert, B., \& Burack, J. (2006). Enhanced perceptual functioning in autism: An update, and eight principles of autistic perception. Journal of Autism and Developmental Disorders, 36(1), 27-43.

Perlovsky, L. (2009). Language and cognition. Neural Networks, 22, 247-257.

Ritvo, R. A., Ritvo, A. R., Guthrie, D., \& Ritvo, M. J. (2008). Clinical evidence that Asperger's disorder is a mild form of autism. Comprehensive Psychiatry, 49, 1-5.

Schmand, B., Lindeboom, J., \& Van Harskamp, F. (1992). Nederlandse leestest voor volwassenen $(N L V)$. Lisse: Swets \& Zeitlinger.

Snowling, M., \& Frith, U. (1986). Comprehension in 'Hyperlexic' readers. Journal of Experimental Child Psychology, 42, $392-415$. 